\title{
Rate and Predictors of Depression among Selected Under Graduates and Post Graduate Students of Hazara University
} Mansehra, Pakistan

\author{
Aqsa Bibi ${ }^{1}$, Ehsan Humayun ${ }^{1 *}$, Sundus Bibi ${ }^{2}$, Atif Ur Rehman ${ }^{1}$, \\ Nodia Shujaat ${ }^{1}$, Imran Ullah $^{1}$
}

\section{ABSTRACT}

Mental health issues in university students are important problem which are needed to be addressed on priority basis according to the epidemiological data. Objective of current study were the screening of Post graduated and under graduates of Hazara University Garden Campus for assessing the rate of depression and its predictors among them. Total 600 students were approached, 300 post graduate students and 300 under graduate students data were collected by means of questionnaire. Beck Depression scale used as standard and questions were prepared according to it to assess major factors of depression. Response rate of students was reported 436/600, 209 under graduates and 227 post graduates respectively. In under graduates minimal to mild depression was reported $94.74 \%$ however only $5.26 \%$ students had moderate depression. On other hand $98.68 \%$ post graduates fall in mild to moderate degree of depression while moderate depression was reported in only $1.32 \%$ students. Interestingly none of student falls under category of severe depression. Major cause of depression among all graduates was academic stress as it is $73.68 \%$ and $54.60 \%$ in under graduates and post graduates respectively. Universities and health authorities should done studies among students to determine rate of depression and steps should be taken to minimize causes of depression among students so they can attain a good mental health status.

Keywords: Depression, Anxiety, Fatigue, epidemiology, academic stress.

Men's mental health status is its major ability to seek out the hurdles and ultimate issues of life. Among University graduates the most prevailing disorder observed is depression and epidemiology of MDD (major depressive disorder) is $8 \%-20 \%$ in student population. ${ }^{1}$ Depression is the most frequent mental issue that has character and symptoms like loss of appetite, loss of concentration, misery and lack of intrest. ${ }^{2}$ Specific precautionary measures had

\footnotetext{
${ }^{1}$ Department of Biochemistry, Hazara University Garden Campus Mansehra, KPK, Pakistan

${ }^{2}$ Department of Psychology, Hazara University Garden Campus Mansehra, KPK, Pakistan

* Co Responding Author

(C) 2015 I A Bibi, E Humayun, S Bibi, A Rehman, N Shujaat, I Ullah; licensee IJIP. This is an Open Access Research distributed under the terms of the Creative Commons Attribution License (http://creativecommons.org/licenses/by/2.0), which permits unrestricted use, distribution, and reproduction in any Medium, provided the original work is properly cited.
} 


\section{Rate and Predictors of Depression among Selected Under Graduates and Post Graduate Students of Hazara University Mansehra, Pakistan}

to be taken for individual who is at high risk of depression or the individual showing sub clinical symptoms of depression by involving him in environmental and family functions. WHO declared depression in 2001 as the $4^{\text {th }}$ major cause of psychological disorders and untimely loss of life throughout world, and it is predictability that by the year 2020 it could be the $2^{\text {nd }}$ major cause of cardiovascular disorders. ${ }^{3}$ Different studies are conducted among graduates throughout globe to find out the rate and major causing predictors of depression. ${ }^{4}$

NIMH (National Institute of Mental Health) reported different sign and symptoms of depression are fatigue, failure of decision making, increased energy demand and lack of concentration. Major causes of depression are relationship issues, competitive environment, work overload, ethical issues, personal issues, and death of love ones. ${ }^{5}$ Anxiety and depression among graduates resulted in different behavioral issues such as extremism and it is also the basic cause of negative management in life issues i-e use of drugs, smoking, excessive use of alcohol, loss of appetite and improper metabolism all these factors cause outcome of poorer health status. ${ }^{6}$ Students are the future of any nation and their status of mental health should be addressed because depression is the common issue among graduates also it is directly related to their professional life. ${ }^{7}$

Literature shows that depression is the major causative problem not only effecting students performance in educational institutes but also resulted in suicides due to low morality. ${ }^{8}$ When students move from fundamental studies to their higher studies it is observed that rate of depression elevated as well. ${ }^{9}$ Field of education is major area of concern among students as they have to face certain stressful and emotional factors while evaluating from a student to a professional. ${ }^{10}$ These factors put negative impacts on student performance and its studies because of mental distress. ${ }^{11}$

In this study no. of techniques were used in order to find out the major role and cause of depression among students. This study based on the self reported probable causes of depression by the students and its co-relation. Main objective of current study is the assessment of rate of depression, its major causes and severity of depression among graduates of Hazara University Garden Campus Mansehra

\section{METHODOLOGY}

\section{STUDY PERIOD}

Present surveillance was conducted at Hazara University Garden Campus Mansehra started from first week of December, 2014 to the last week of January, 2015. All graduates were approached through Quota sampling method.

\section{STUDY POPULATION}

Total 600 under graduate and post graduate students of different departments were screened from Hazara University Garden Campus Mansehra. At first students were convinced to fill 


\section{Rate and Predictors of Depression among Selected Under Graduates and Post Graduate Students of Hazara University Mansehra, Pakistan}

questionnaire designed according to Beck depression scale.

\section{DATA COMPILATION}

PTQ (pre tested questionnaire) and CST (convenience sampling technique) were used for data collection. PTQ was compiled and after successful analysis is used for the assessment of target samples. This questionnaire was designed by using standardized Beck depression scale but is with some modifications according to study area by designing self made questions to find out the major factors of depression. For statistical analysis SPSS 16 were used.

\section{RESULTS \& DISCUSSION}

In this study 600 graduates were screened 300 under graduate and post graduate students respectively were approached from first week of December, 2014 to last week of January 2015. Response rate of all students reported 436/600, while 209/300 (69.66\%) of undergraduates (male 83, female 126) and 227/300 (75.66\%) of post graduates (male 159, female 70). Mean age was reported 22.19 years $(S . D=1.655)$ and 28.40 years $(S . D=3.525)$ for under graduates and post graduates respectively. Statistical analysis shows its significance as p-value reported as 0.01 as shown in Table $1.79 .42 \%$ of under graduates reported minimal depression, $15.31 \%$ mild depression and 5.26\% student's shows moderate depression level none of under graduates responders show sign of severe depression Figure 1. Major predictors of depression among under graduates were academic stress (73.68\%), work overload (69.37\%), competitive environment (57.41\%), personal issues $(55.97 \%)$ and discriminating environment $(40.66 \%)$ as shown in Figure 2. A total of $92.07 \%$ of post graduates show signs of minimal depression, $6.60 \%$ mild depression and $1.32 \%$ student's shows moderate depression and interestingly also none of post graduates student show signs of severe depression Figure 3. Major predictors of depression in post graduates were work overload $(55.10 \%)$, academic stress $(54.60 \%)$, competitive environment (50.20\%), discriminating environment (41.90\%), and personal issues (39.20\%) Figure 4. From both categories of under graduates and post graduates majority of students show symptoms of minimal and mild degree of depression. And only 14 students from both categories show moderate depression and statistical significant $\mathrm{P}$ value is 0.01 Figure 5 .

In current study only few of students were moderately depressed while none of student having severe depression and results of our study show that students having much lower depression as it is indicated $40 \%$ respondents having depression in Zaman S et al., study. ${ }^{12}$ Similar study report by the students of Agha Khan University Karachi, Pakistan showed 33.66\% students having moderate depression while $66.34 \%$ students suffering from minimal and mild level of depression. ${ }^{13}$ However in contrast current study show better results as it show less depression in students screened. Students of Azad Jammu Kashmir University conducted a survey near to the end of academic year and reported that end of academic year also provoke stress level among students. ${ }^{14}$ Our study was in the mid of academic year so justifies low depression rate among students. Study from Maharashtra, India shows mild and moderate depression among 24.71\% students while our study shows minimal to mild level of depression at higher rates in contrast. ${ }^{15}$ 
Study from UK reports 10\%-18\% students having depression while a study from turkey shows a higher level of depression i-e 30\% also study from Vietnam reported 39.6\% undergraduates having depression. ${ }^{16,17,18}$ Factors causing depression reported by the study from Agha Khan University Karachi, Pakistan was reported by $33.7 \%$ participants as colleagues support and working hours. ${ }^{19}$ An Indian study reports chronic illness, family history, parental losses and failure of love affairs as major factors of causing depression. ${ }^{20}$ Study by Khan et al., make reported family history, abusing and loss of loved ones are the factors responsible for depression among students. ${ }^{21}$ Ibrahim et al., conducted a study in Saudi Arabia reported work burdens along with failure in obtaining good grades and emotional issues are the major factors causing depression. ${ }^{22}$ Current study reports academic stress, personal issues, work overload, discriminating working environment relationship issues, as predictors of depression among graduates which are very much justified by other studies.

\section{CONCLUSION}

In current study majority of students have minimal and mild depression that concluded majority of students have depression. Post graduate students have more relaxed mental health status than undergraduates. All students were more prone to depression due to extra academic stress followed by work load. So studies should be conducted to be aware of rate of depression at regular intervals because any degree of depression can leads patients to distraction and is threat to its life, so life of students should not undetermined at any level.

Table 1: Comparison of rate of depression among Gender

\begin{tabular}{|l|c|c|}
\hline Rate of Depression & \multicolumn{2}{|c|}{ Gender } \\
\hline Minimal & Male & Female \\
\hline Mild & 220 Students & 155 Students \\
\hline Moderate & 14 Students & 33 Students \\
\hline Severe $\quad$ 8 Students & 6 Students \\
\hline \multicolumn{1}{|c|}{$\mathbf{0 . 0 1}$} \\
\hline
\end{tabular}


Rate and Predictors of Depression among Selected Under Graduates and Post Graduate Students of Hazara University Mansehra, Pakistan

Fig 1: Rate of depression among under graduates

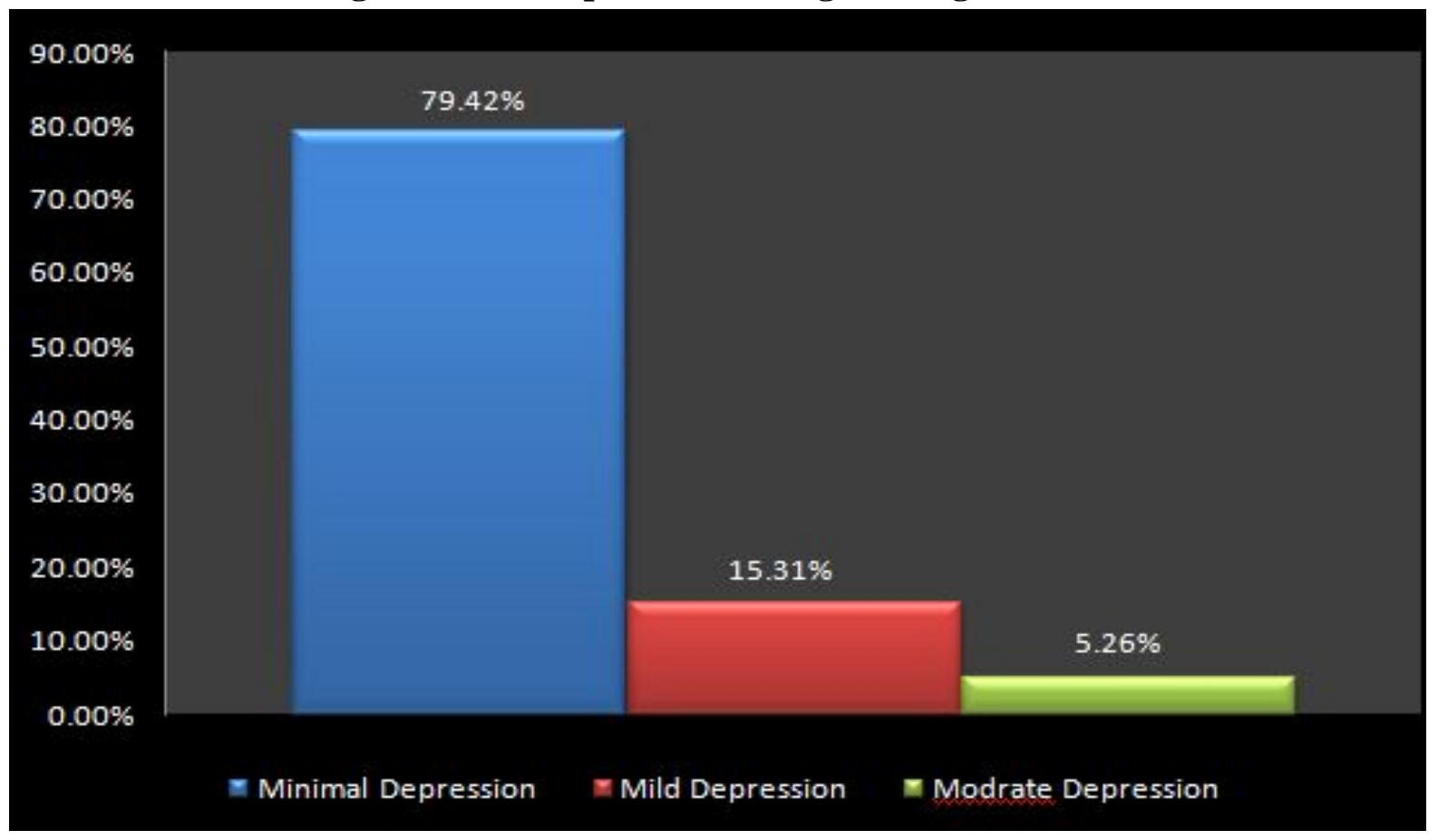

Fig 2: Predictors of depression among under graduates

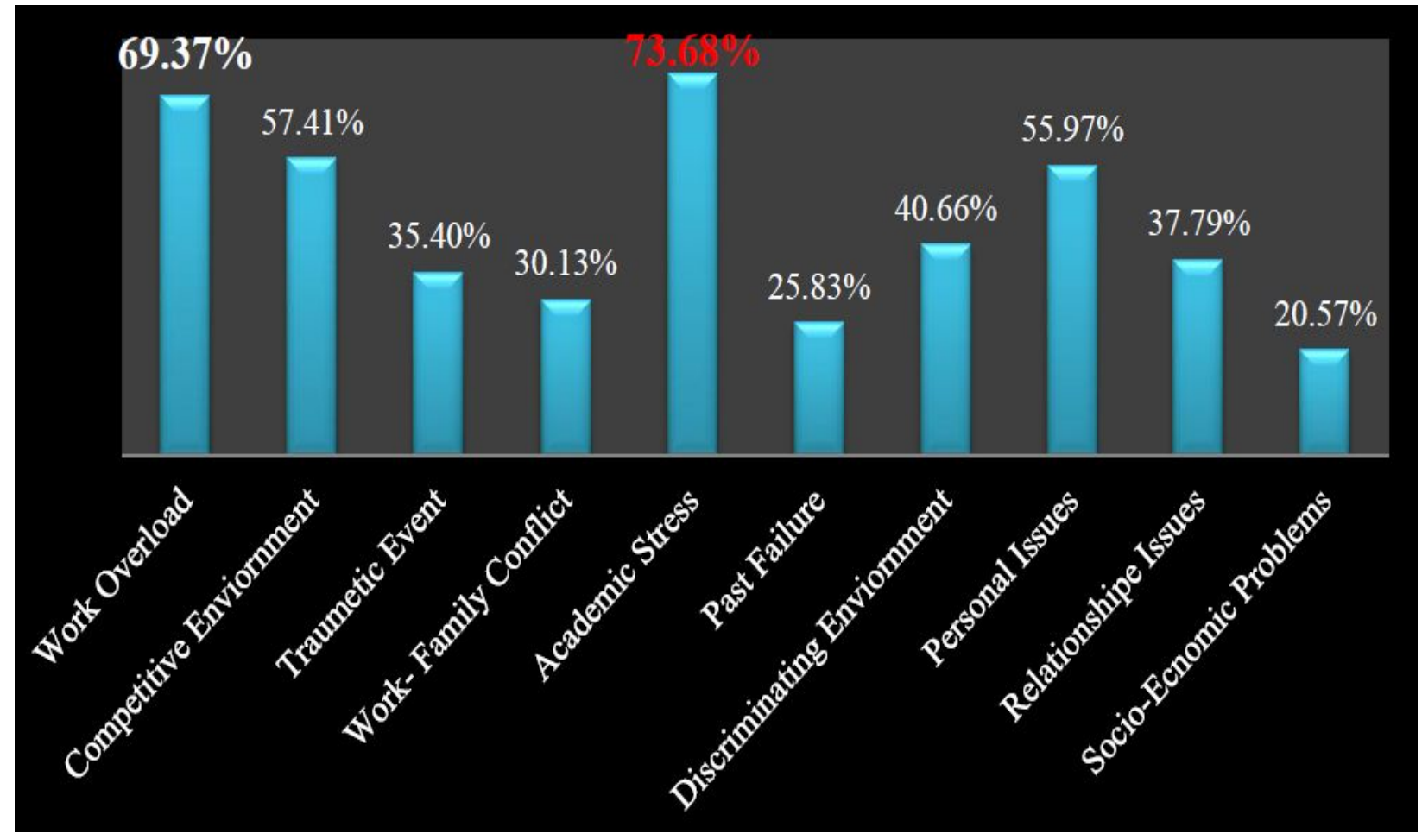

(C) The International Journal of Indian Psychology | 20 
Rate and Predictors of Depression among Selected Under Graduates and Post Graduate Students of Hazara University Mansehra, Pakistan

Fig 3: Rate of depression among post graduates

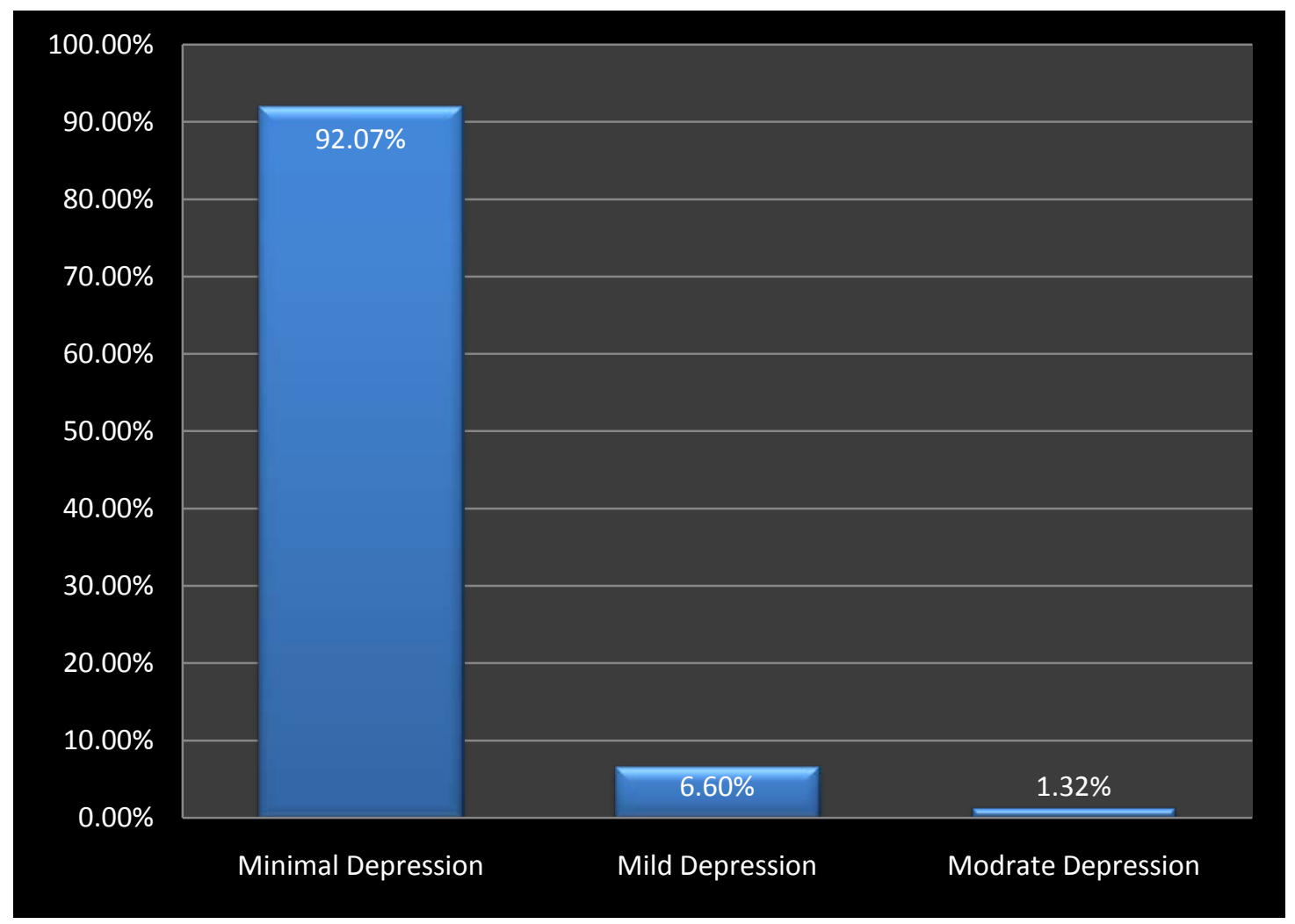

Fig 4: Predictors of depression among Post-graduates

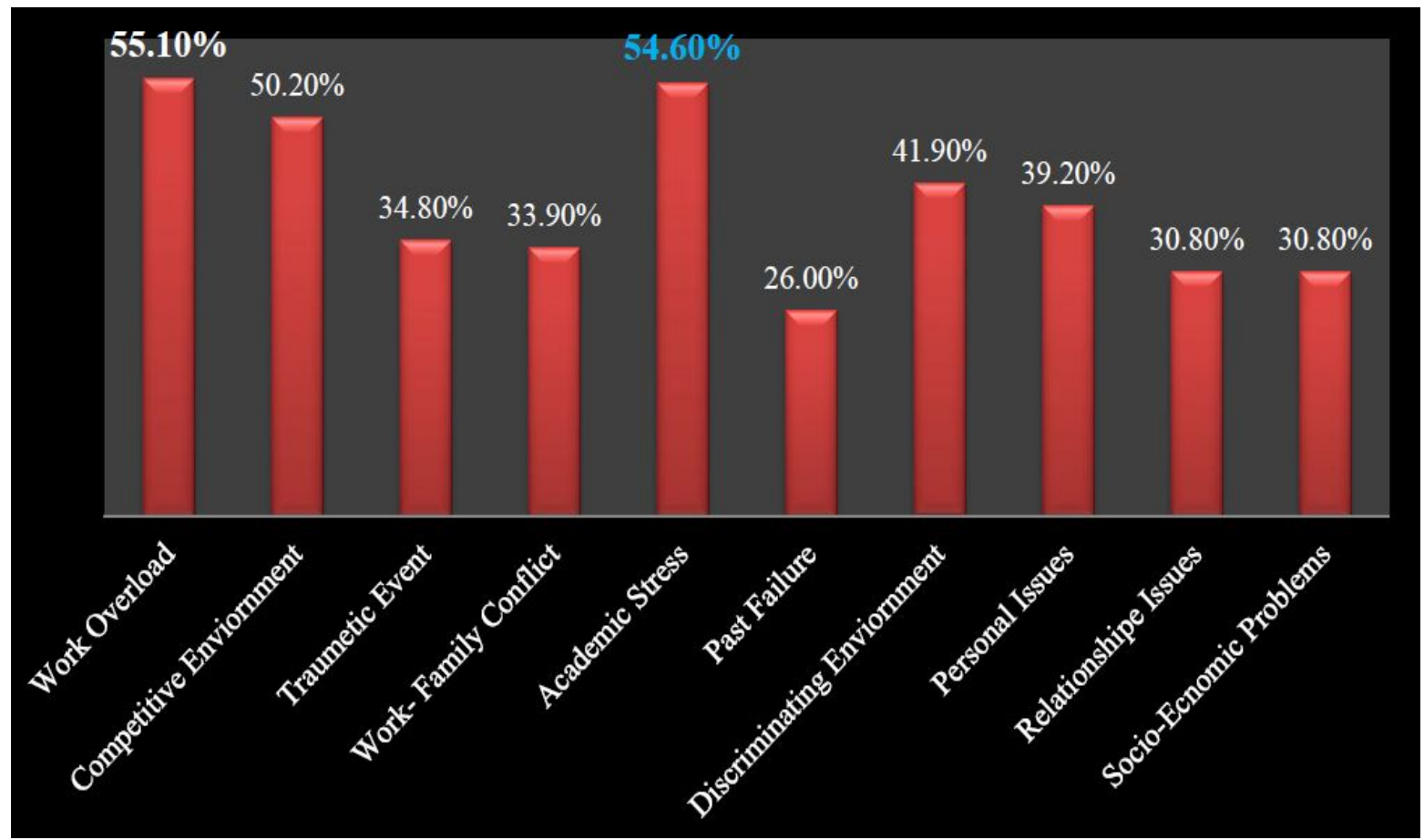

(C) The International Journal of Indian Psychology | 21 
Fig 5: Comparison of rate of Depression among under graduate and post graduate students

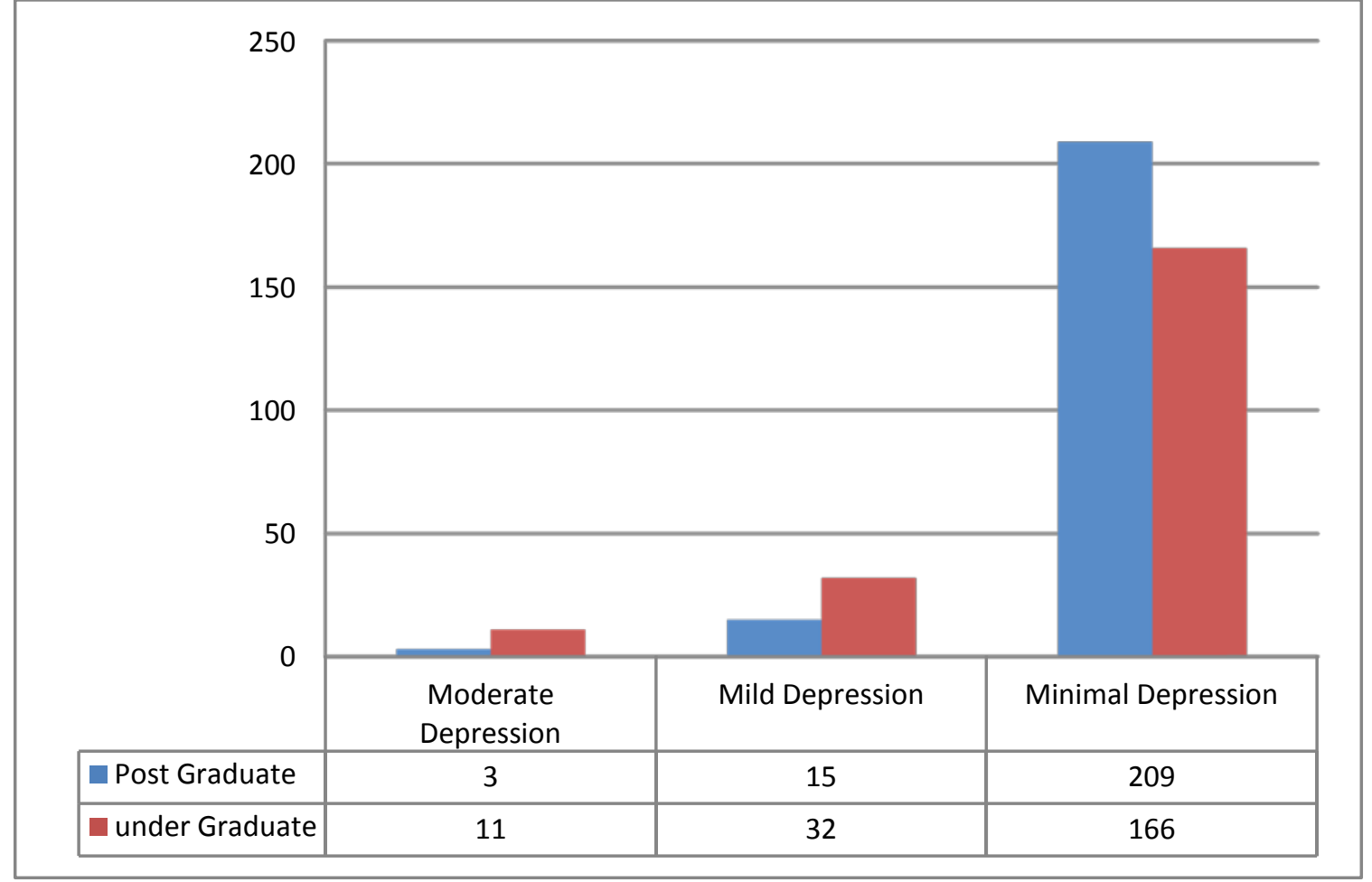

\section{REFERENCE}

1. Ahmed I, Banu H, Al-Fageer R, Al-Suwaidi R. Cognitive emotions: depression and anxiety in medical students and staff. J Crit Care. 2009; 24:e1-7.

2. $\quad$ www.ncbi.nlm.nih.gov/pubmedhealth/PMH0001941

3. Schutter DJ, Honk VJ. A framework for targeting alternative brain regions with repetitive transcranial magnetic stimulation in the treatment of depression J Psych Neurosci 2005; 30(2):81-82.

4. Tyssen R, Hem E, Vaglum P, Gronvold NT, Ekeberg O. The process of suicidal planning among medical doctors: predictors in a longitudinal Norwegian sample. J Affect Disord 2004; 80(2-3):191-8.7.

5. Rees CE, Bradley P, McLachlan JC. Exploring medical students' attitudes towards peer physical examination Med Teach. 2004; 26:86-88.

6. $\quad$ Firth J. Levels and sources in medical students. BMJ. 1986; 292:11 77-80.

7. Eisenberg D, Hunt J, Speer N. Mental health in american colleges and universities: variation across student. J NervMent Dis. 2013; 201:60-7.

8. Sreeramareddy CT, Shanker PR, Binu VS, Mukhopadhyay C, Ray B, Menezes RG. Psychological morbidity, sources of stress and coping strategies among undergraduate medical students of Nepal.BMC Med Edu2007; 7:26. 
9. Helmers KF, Danoff D, Steinert Y, Leyton M, Young SN. Stress and depressed mood in medical students, law students, and graduate students at McGill University. Acad Med. 1997; 72: 708-714.

10. Sohail N. Stress and academic performance among medical students. J Coll Physicians Surg Pak. 2013; 23: 67-71.

11. Dahlin M, Joneberg N, RunesonB. Stress and depression among medical students: a cross sectional study. Med Education 2005; 39(6): 594-604.

12. Zaman S, Rahim MA, Khan AH, Habib SH, Rahman MM, Ahsan MS et al; Prevalence of Depression among Post-Graduate MedicalTrainees: A Multi-Centre Survey; BIRDEM medical Journal, 2014; Vol 4, No. 1; 20-1.

13. Yousuf A, Ishaque S, Qudwai W. Depression and Its Associated Risk Factors in Medical and Surgical Post-graduate Trainees at A Teaching Hospital: A Cross- sectional Survey From A Developing Country. JPMA 2011; 61:9 68-72.

14. Muhammad S. Khan, Sajid Mahmood, Areef Badshah, Syed U. Ali, Yasir Jamal, Jinnah Postgraduate Medical Center, Karachi, Departments of Medicine and Medical Students, Aga Khan University, Karachi.

15. Sahu PC, Inamdar IF, Obaidulla M, Tambe S, Gadeker RD, Sonkar VK, et al. Study of depression among medical students of different pathies in Nanded City, Maharashtra. J Evol Med Den Sci; Published online on 31 ${ }^{\text {st }}$ March,2013.

16. Karaoglu N, Seker M. Anxiety and depression in medical students related to desire for and expectations from a medical career. West Indian Med J 2010;59 (2):196-202.

17. Quince TA, Wood DF, Parkel RA, Benson J. Prevalence and persistence of depression among under-graduate medical students: a longitudinal study at one UK medical school. BMJ Open. 2012; 2(4): e001519. Published online on August 9, 2012. doi: 10.1136/bmjopen-2012-001519.

18. Ms. QuyenDinh Do,Depression And Stress Among the first year medical Students in university of MEDICINE AND PHARMACY HOCHIMINH CITY, VIETNAM ,Chulalongkorn University Academic Year 2007.

19. Basnet B, Jaiswal M, Adhikari B, Shyangwa PM, Depression Among Undergraduate Medical Students, Kathmandu university medical journal,vol 10 ,no 3 (2012).

20. Saipanish R. Stress among medical students in a Thai medical school. Med Teach.2003; 25:5 02-6.

21. Khan MS, Mahmood S, Badshah A, Ali SU, Jamal Y. Prevalence of depression, anxiety and their associated factors among medical students in Karachi, Pakistan. J Pak Med Assoc 2006; 56:583-6.

22. Nahla IBRAHIM, Dania AL-KHARBOUSH, Lamis EL-KHATIB, Ahd AL-HABIB and Dana ASALI, Prevalence and Predictors of Anxiety and Depression among Female Medical Students in King Abdulaziz University, Jeddah, Saudi Arabia. 